\title{
A Survey of Utilization and Effectiveness of Insecticide - Treated Bednets (Itns) As Intervention Strategy in Malaria Transmission among Pregnant Women in a Rural Community in Ebonyi State, South Eastern Nigeria
}

\author{
${ }^{1}$ Elom, Michael O., ${ }^{2}$ Alo, Moses N., ${ }^{1}$ Ugah, Uchenna I., ${ }^{1}$ Okeh, Emmanuel N., \\ and ${ }^{1}$ Ibiam, Gideon A. \\ ${ }^{I}$ Departnent of Medical Laboratory Science, Faculty of Health Sciences and Technology, Ebonyi State \\ University, Abakaliki, Ebonyi State. \\ ${ }^{2}$ Department of Biological Science, Faculty of Science and Technology, Federal University, Ndufu-Alike Ikwo,
} Ebonyi State.

\begin{abstract}
One hundred and twenty eight (128) pregnant women of various age groups and gravidities who were at their different trimesters were interviewed to match their use of ITNs with their episodes of malaria. Structured closed ended interviewer administered questionnaire was used to collect data. The age range of the women was between 15 and 47 years. All of them owned insecticide - treated bed nets while only few of the owners utilized them. All the women attended antenatal care (ANC) at the government health care centres. Forty six (35.94\%), 42(32.81\%), and 40(31.25\%) were primigravidae, secundigravidae, and multigravidae respectively. Thirty eight $(29.70 \%), 47(36.72 \%)$, and $43(33.60 \%)$ were at their $1^{\text {st }}, 2^{\text {nd }}$ and $3^{\text {rd }}$ trimesters respectively. Thirty seven (28.91\%) of the entire sampled population utilized their bed nets, with those within the age group of 15 - 19 years making more use of their bed nets while those at 40 years and above made least use of theirs. Women at their $2^{\text {nd }}$ trimesters of pregnancy utilized their bed nets most. Women within the age bracket of 15-19 years and 20-24 years utilized their bed nets better and experienced an average frequency of malaria episodes of 1 (once) while those who were 40 years and above made the least use of the bed nets and experienced the highest average frequency of malaria episodes of 5. An average frequency of malaria episode of 6 was observed among the primigravidae, while the secundigravidae who highly utilized their bed nets had an average episode of 4 . Women in their $2^{\text {nd }}$ trimesters utilized bed nets most and had the least average malaria episode of 3 . Those in their $1^{\text {st }}$ and $3^{\text {rd }}$ trimesters each had an average malaria episode of 6.
\end{abstract}

Keywords: Utilization, Effectiveness, Bed nets, Malaria, Pregnancy.

\section{Background}

Malaria is a serious public health problem in most parts of the globe. It is a leading cause of death and disease in many developing countries. Malaria occurs mostly in poor, tropical and subtropical areas of the world. In Africa, malaria transmission is maintained by the presence of a very efficient vector, Anopheles gambiae, predominance of Plasmodium falciparum, optimum local conditions, scarce resources, poor environmental conditions and socio - politico - economic instabilities. The World Health Organization stated in the World Malaria Report 2011 that as at 2010, about 3.3 billion people live in areas at risk of malaria transmission in 106 countries and territories [1]. Two hundred and sixteen million clinical episodes and 655,000 deaths have been attributed to malaria and an estimated $91 \%$ deaths were in the African region. Africa is a malaria endemic region where approximately 25 million women become pregnant annually and are at risk of Plasmodium falciparum infections during pregnancy [2].

Malaria accounts for $60 \%$ of outpatient visits and $30 \%$ of hospitalization among children under 5 years of age in Nigeria [3]. It is a vector - borne devastating infectious disease. Pregnant women, children under 5 years of age and immunocompromised individuals are the people with the highest risk of malaria. Pregnant women infected with malaria usually have more severe symptoms and outcomes with higher rates of miscarriages, intrauterine damage, premature delivery, low birth weight neonates, neonatal deaths, severe anaemia and maternal death $[4,6]$. Malaria - associated maternal anaemia and low birth weight babies are more common in primigravidae than in multigravidae [6]. This is because the former have not acquired the natural immunity to placental malaria [7].

A mortality rate of about $50 \%$ attributed to severe malaria disease has been established in pregnant women [2]. Several measures such as use of insecticide - treated bednets, indoor residual spraying, larviciding, environmental management practices, community and public health education, intermittent preventive treatment in pregnancy (IPT) have been carried out in control of both malaria vectors and parasites in Nigeria. 
Environmental bioaccumulation, ecotoxicity, insecticide resistance, anthropogenic attitudes and practices, side effects and drug resistance have respectively reduced other control measures to second options of choice, leaving insecticide - treated bed nets (ITNs), the safest and most efficacious malaria control intervention.

Consistent use of insecticide - treated bed nets can reduce malaria transmission up to $90 \%$ [8]. Use of ITNs among pregnant women is associated with a lower prevalence of malaria infection, fewer premature births and significant reductions in all cause maternal anaemia $[9,10]$. In the year 2000, when ITNs were introduced to the public only $7 \%$ of Nigerians had the awareness. Between 2000 and 2004, the awareness increased from 7\% to $60 \%$ [11]. Since then, there has been increased awareness of ITNs. In fact, current awareness of ITNs by Nigerians is supposed to have been close to $100 \%$. But it is disheartening that despite such awareness and high prevalence of malaria in pregnancy and its associated problems, many households still either do not have or use the ITNs.

\section{Study Area}

\section{Methods}

The study was undertaken in all the villages within Oshiri Community in Onicha LGA of Ebonyi State, South Eastern Nigeria. Ebonyi State lies approximately within longitude $7^{0} 30$ and $8^{0} 30 \mathrm{E}$ and latitude $5^{0} 40$ and $65^{0} 45 \mathrm{~N}$. The vegetation of the state is predominantly tropical rainforest, with mean annual rainfall of $2100 \mathrm{~mm}$. Rainy and dry seasons are the two seasons of Nigeria. The rainy season starts from April to October while the dry season begins from November to April.

Oshiri community is a rural community surrounded by bushes, rivers, streams, small water bodies, pools and ponds. Although most of these water bodies recede during dry season, the environmental setting encourages breeding of mosquitoes. The community has some government health centres, health posts and some traditional birth homes $(\mathrm{TBH})$, being managed by traditional birth attendants (BTA).

\section{Study Population}

The study population was 128 pregnant women who owned and used ITNs and attended antenatal care centres (ANC) of the government health centres in the community. The women were of various groups and gravidities and at their different trimesters. The age range of the women was between 15 and 47 years. Informed consents were sought and obtained from the women before their enrollment in the study.

\section{Data Collection and Analysis}

Data were collected by the use of structured closed ended interviewer administered questionnaire. Malaria episodes among the women were established through symptoms, confirmed by positive malaria slides processed by standard Giemsa staining techniques. Home visits were made to ascertain their use of the nets. The data generated were analyzed using simple descriptive statistics.

\section{Results}

A total of 128 pregnant women of varying age groups, who owned and used ITNs and attended antenatal clinics were involved in the study. Majority of the women, 34(26.56\%) fall within the age limit of $20-$ 24 years while only 5(3.91\%) were 40 years old and above (Table 1$)$. Forty six $(35.94 \%)$ were primigravidae while $40(31.25 \%)$ were multigravidae (Table 1). The distribution of the women according to trimester of pregnancy indicate that majority of them $47(36.72 \%)$ were in the second trimesters and the least of them 38(29.70) were in their first trimesters (Table 1).

Table 2 depicts utilization of bed nets according to ages, gravidities and trimesters of pregnancies of the women. Out of the 128 women sampled, 37(28.91\%) utilized their bed nets at various levels of compliance.

Women within the age group of $15-19$ utilized their bed nets most while those at 40 years or more made the least use of theirs. Their percentage utilization per group numbers sampled was 38.46 and 20.00 respectively. Within the 37 women that utilized their bed nets, those within the age group of 20 to 24 years made the most use of their nets while those who were 40 years and above made the least use of theirs $[11(8.59 \%)$ and $1(0.78 \%)]$ respectively.

The secundigravidae utilized their bed nets most while the primigravidae made the least use of theirs.

Their percentage utilizations per group numbers sampled were 35.71 and 22.50 respectively while their numbers and percentages within the users of the nets were $15(11.72 \%)$ and $9(7.03 \%)$ respectively.

Women at their second trimesters of pregnancy utilized their bed nets most, $16(12.50 \%)$ and $34.04 \%$ within the net users and group number sampled respectively.

When the bed nets utilization was used to compare the average frequencies of malaria episodes within age groups, pregnant women within the age brackets of $15-19$ and $20-24$ years utilized their bed nets better 
and experienced the least frequencies of malaria episodes. Women who were 40 years old and above made the least use of their bed nets and had the highest average frequencies (5 times) of malaria episodes (Table 3 ).

The primigravidae made the least use of their ITNs and had the highest average frequencies (6 times) of malaria episodes while the secundigravidae highly utilized theirs and experienced the least number of episodes (4 times) of malaria.

Pregnant women in their second trimesters utilized their bed nets most and experienced the least number ( 3 times) of malaria episodes while those at their first and third trimesters poorly utilized their own and experienced higher frequencies (6 times each) of malaria episodes (Table 3 ).

\begin{tabular}{|c|c|}
\hline $\begin{array}{l}\text { Age Groups } \\
\text { (Years) }\end{array}$ & Number (\%) of Subjects Sampled \\
\hline $15-19$ & $26(20.31)$ \\
\hline $20-24$ & $34(26.56)$ \\
\hline 25-29 & $25(19.53$ \\
\hline $30-34$ & $22(17.19)$ \\
\hline $35-39$ & $16(12.50)$ \\
\hline$\geq 40$ & $5(3.91)$ \\
\hline Total & $128(100)$ \\
\hline \multicolumn{2}{|l|}{ Gravidities } \\
\hline Primigravidae & $46(35.94$ \\
\hline Secundigravidae & $42(32.81$ \\
\hline Multigravidae & $40(31.25)$ \\
\hline Total & $128(100)$ \\
\hline \multicolumn{2}{|l|}{ Trimesters } \\
\hline $1 \mathrm{st}$ & $38(29.70)$ \\
\hline 2nd & $47(36.72)$ \\
\hline $3 \mathrm{rd}$ & $43(33.60)$ \\
\hline Total & $128(100)$ \\
\hline
\end{tabular}

Table 2: Utilization Of Bednets According To Age Groups, Gravidities And Trimesters Of The Subjects

\begin{tabular}{|c|c|c|c|}
\hline $\begin{array}{l}\text { Age Groups } \\
\text { (Years) }\end{array}$ & $\begin{array}{l}\text { Number } \\
\text { of } \\
\text { Subjects } \\
\text { Sampled }\end{array}$ & $\begin{array}{l}\text { Number } \\
(\%) \text { of } \\
\text { Utilization }\end{array}$ & $\begin{array}{l}\% \text { Utilization per } \\
\text { Group Number Sampled }\end{array}$ \\
\hline $15-19$ & 26 & $10(7.81)$ & 38.46 \\
\hline $20-24$ & 34 & $11(8.59)$ & 32.35 \\
\hline $25-29$ & 25 & $6(4.69)$ & 24.00 \\
\hline $30-34$ & 22 & $5(3.91)$ & 22.73 \\
\hline $35-39$ & 16 & $4(3.13)$ & 25.00 \\
\hline$\geq 40$ & 5 & $1(0.78)$ & 20.00 \\
\hline Total & 128 & $37(28.91)$ & 162.54 \\
\hline \multicolumn{4}{|l|}{ Gravidities } \\
\hline Primigravidae & 40 & $9(7.03)$ & 22.5 \\
\hline Secundigravidae & 42 & $15(11.72)$ & 35.71 \\
\hline Multigravidae & 46 & $13(10.16)$ & 28.26 \\
\hline Total & 128 & $37(28.91$ & 86.47 \\
\hline \multicolumn{4}{|l|}{ Trimesters } \\
\hline $1 \mathrm{st}$ & 38 & $10(7.81)$ & 26.32 \\
\hline 2nd & 47 & $16(12.50)$ & 34.04 \\
\hline $3 \mathrm{rd}$ & 43 & $11(8.60)$ & 25.58 \\
\hline Total & 128 & $37(28.91)$ & 85.94 \\
\hline
\end{tabular}


Table 3: Utilization Of Bednets And Frequencies Of Malaria Episodes Among The Subjects

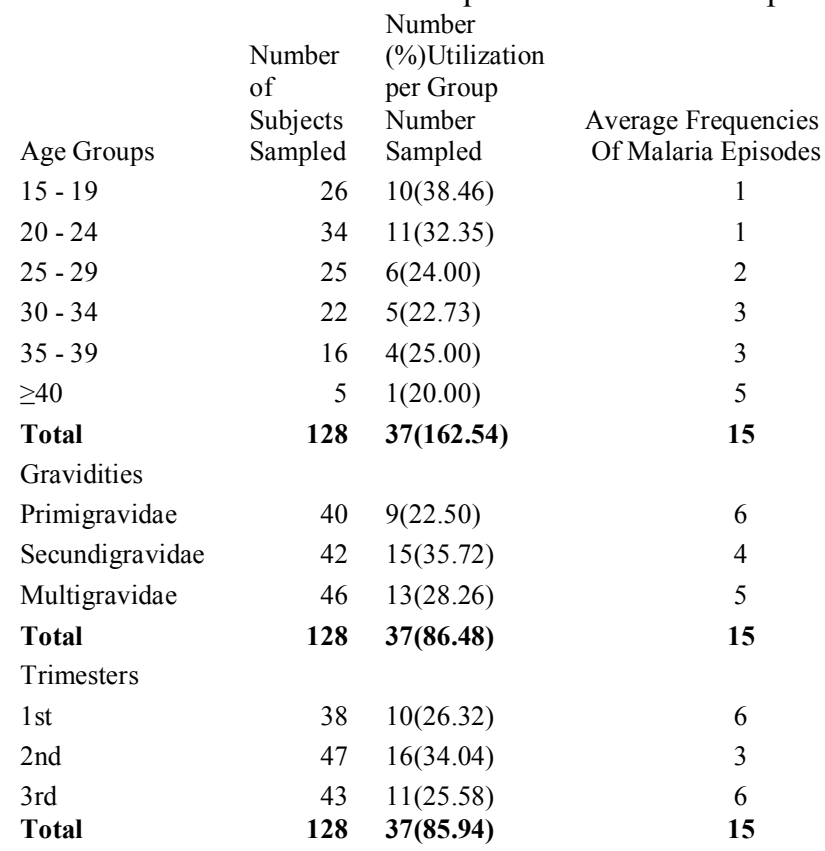

\section{Discussion}

A total of 128 pregnant women between the age range of 15 and 47 years who attended antenatal clinics at heath centres and who were at their different gravidities and trimesters were interviewed to determine their usage of insecticide treated bed nets (ITNs) and ascertain the frequencies of malaria episodes among them (Table 1).

Several epidemiological surveys indicate that there have been a wide coverage of distribution of ITNs in Nigeria, but very poor utilization of the nets have been severally reported to undermine the efforts in the malaria control fight. The present study indicated a poor utilization of the ITNs. Thirty seven $(28.91 \%)$ out of 128 correspondents made use of their nets (Table 2). The findings of the present study are in line with those of [12-14]. All of which indicated poor utilization rates of the nets of $11.5 \%, 4.3 \%, 33 \%$ and $31 \%$ respectively. Ordinioha [15] also reported a very poor use of the nets.

The use of insecticide treated bed nets (ITNs) has been reported by several previous studies to be efficacious in reduction of malaria transmission through the reduction of infective mosquito bites and episodes of malaria. Seventy to $90 \%$ reduction of infective mosquito bites has been reported in various geographical settings $[2,16]$. The present study indicated that higher utilization of the nets resulted in the reduction of malaria episodes across the age groups, gravidities and trimesters (Table 3). The reduction in malaria episodes conforms to the findings of previous studies including that of Igwe and colleagues [17] which reported a statistically significant reduction $(\mathrm{p}<0.003)$ in the number of episodes of uncomplicated malaria among primigravidae.

It is disappointing that despite the wide distribution coverage of the nets, many people who own them do not utilize them. Therefore, to win the fight against malaria in Nigeria, proper public health education and sensitization is advocated.

\section{References}

[1]. World Health Organisation. World Malaria Report Fact sheet. 2011

[2]. Aluko, J. O. and Abimbola, O. O. Utilization of insecticide - treated bednets during pregnancy among postpartum women in Ibadan, Nigeria: a cross sectional study. BMC Pregnancy and Childbirth. 2012, 12: 21 - 28

[3]. United States Embassy in Nigeria. Nigeria malaria fact sheet. 2011. Accessed 14/02/2013.

[4]. Schantz - Dunn, J and Nour, N. M. Malaria and pregnancy: a global health perspective. Review of Obstetrics and Gyneacology. 2009, 2(3): $186-192$.

[5]. Lagerberg, R. E. Malaria in pregnancy: a literature review. Journal of Midwifery Women's Health. 2008, 53(3): 209 - 215.

[6]. Shulman, C and Dorman, E. Clinical features of malaria in pregnancy. In: Warrel D and Gilles, H. M. (eds). Essential Malariology. $4^{\text {th }}$ ed. Arnold, London. 2003: $219-235$

[7]. Tako, E. A., Zhou, A., Lohoue, J., Leke, R., Taylor, D. W and Leke, R.S.G. Risk factors for placental malaria and its effect on pregnancy outcome in Yaounde, Cameroon. American Journal of Tropical Medicine and Hygiene. 2004, 72(3): 236 - 245.

[8]. Giming, J. E., Vulule, J. M., Lo, T. Q., Kamau, L., Kokzak, M. S., Philips-Howard, P.A., Mathenge, E. M., Terkuile, F. O., Nahlen, B.L., Hightower, A. W and Hawley, W. A. Impact of permethrin - treated bednets on entomological indices in an area of intense year round malaria transmission. American Journal of Tropical Medicine and Hygiene. 2003, 68 (suppl 4): 16 - 22.

[9]. D’Alessandro, U., Langerock, P., Bennett, S., Francis, N., Cham, K., and Greenwood, B. M. The impact of a national impregnated bednet programme on the outcome of pregnancy in primigravidae in the Gambia. Transactions of Royal Society of Tropical Medicine and Hygiene. 1996, 90:487 - 492. 
[10]. Terkuile, F. O., Terlouw, D. J., Phiilips - Howard, P. A., Hawley, W. A., Friedman, J. F., Kariuki, S. K., Shi, Y. P., Kolczak, M. S., Lal, A. A., Vulule, J. M., and Nahlen, B. L. Reduction of malaria during pregnancy by permethrin - treated bed nets in an area of intense perennial malaria transmission in Western Kenya. Americn Journal of Tropical Medicine and Hygiene 2003, 68(April):100 -107 .

[11]. Baume, C. A and Mavin, C. Gains in awareness, ownership and use of insecticide treated bednets in Nigeria, Senegal Uganda and Zambia. Malaria Journal. 2008, 7:153.

[12]. Yassin, I. M., Rosnah, S and Osman, M. Factors influencing the usage of insecticide treated mosquito nets among pregnant women. International Journal of Health Research. 2010, 3(3): $139-144$

[13]. Amoran, O. E., Senbanjo, I. O and Asagwara, C. E. Determinants of insecticide - treated nets use among youth corps members in Edo State, Nigeria. Biomed Central Public Health, 2011, 11: 728.

[14]. Shedrack, S. P., Bartholomew, M and Addmore, C. An investigation of the use of rectangular insecticide treated nets for malaria control in Chipinge District, Zimbabwe: a descriptive study. The Pan African Medical Journal. 2012, 13: 5

[15]. Ordinioha, B. The use and misuse of mass distributed free insecticide treated bednets in a semi - urban community in Rivers State, Nigeria. Annals of African Medicine., 2012, 11(3): 163 - 168.

[16]. Steketee, R., Nahlen, B., Parise, M and Menendez, C. The burden of malaria in pregnancy in malaria endemic areas. American journal of Tropical Medicine and Hygiene. 2001, 64: $28-35$.

[17]. Igwe, P. C., Inem, V., Ebuechi, O. M and Afolabi, B. M. The effect of insecticide - treated bed net use on malaria episodes, parasitaemia and haemoglobin concentration among primigravidae in a periurban settlement in South Eastern Nigeria. Journal of Rural and Tropical Public Health. 2007, 6:24 - 32. 